\title{
Chagas disease in European countries: the challenge of a surveillance system
}

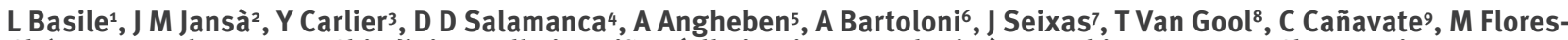

Chávez $^{9}$, Y Jackson ${ }^{10}$, P L Chiodini ${ }^{11}$, P Albajar-Viñas (albajarvinasp@who.int) ${ }^{12}$, Working Group on Chagas Disease ${ }^{13}$

1. Department of Health, Generalitat of Catalonia, Barcelona, Spain

2. Directorate General of Public Health and Foreign Healthcare, Ministry of Health, Social Affairs and Equality, Madrid, Spain

3. Faculty of Medicine, Free University of Bruxelles, Brussels, Belgium

4. French Institute for Public Health Surveillance (Institut de Veille Sanitaire, InVS), Saint Maurice, France

5. Centre for Tropical Diseases, COHEMI network, Hospital S. Cuore, Don Calabria, Negrar, Verona, Italy

6. University Hospital Centre Careggi, COHEMI network, Firenze, Italy

7. Clinical unit of Tropical Diseases, Institute of Hygiene and Tropical Medicine, New University of Lisbon, Lisbon, Portugal

8. Department of Medical Microbiology, University of Amsterdam, Amsterdam, the Netherlands

9. National Centre of Microbiology, Instituto de Salud Carlos III, Madrid, Spain

10. Division of primary care medicine, Geneva University Hospitals and University of Geneva, Geneva, Switzerland

11. Hospital for Tropical Diseases, London, United Kingdom

12. World Health Organization (WHO) Programme on Control of Chagas disease, Department of Control of Neglected Tropical Diseases, WHO, Geneva, Switzerland

13. The members of this group are listed at the end of the article

Basile L, Jansà JM, Carlier Y, Salamanca DD, Angheben A, Bartoloni A, Seixas J, Van Gool T, Cañavate C, Flores-Chávez M, Jackson Y, Chiodini PL, Albajar-Viñas P,

Working Group on Chagas Disease. Chagas disease in European countries: the challenge of a surveillance system.

Euro Surveill. 2011;16(37):pii=19968. Available online: http://www.eurosurveillance.org/ViewArticle.aspx?Articleld=19968

Article published on 15 September 2011

A study of aggregate data collected from the literature and official sources was undertaken to estimate expected and observed prevalence of Trypanosoma cruzi infection, annual incidence of congenital transmission and rate of underdiagnosis of Chagas disease among Latin American migrants in the nine European countries with the highest prevalence of Chagas disease. Formal and informal data sources were used to estimate the population from endemic countries resident in Europe in 2009, diagnosed cases of Chagas disease and births from mothers originating from endemic countries. By 2009, 4,290 cases had been diagnosed in Europe, compared with an estimated 68,000 to 122,000 expected cases. The expected prevalence was very high in undocumented migrants (on average $45 \%$ of total expected cases) while the observed prevalence rate was 1.3 cases per 1,000 resident migrants from endemic countries. An estimated 20 to 183 babies with congenital Chagas disease are born annually in the study countries. The annual incidence rate of congenital transmission per 1,000 pregnancies in women from endemic countries was between none and three cases. The index of underdiagnosis of $T$. cruzi infection was between $94 \%$ and $96 \%$. Chagas disease is a public health challenge in the studied European countries. Urgent measures need to be taken to detect new cases of congenital transmission and take care of the existing cases with a focus on migrants without legal residency permit and potential difficulty accessing care.

\section{Introduction}

Chagas disease is caused by the parasite Trypanosoma cruzi and is considered endemic in 21 Latin American countries. It currently affects around 10 million people in Latin America, and 10 to 30 per cent of cases have developed or will develop cardiac, digestive or nervous system disorders [1]. In the last two decades many efforts have been made to reduce the incidence of Chagas disease in endemic countries [2], but exchange of population between Latin America and Europe, the United States, Australia and Japan has resulted in increased detection of $T$. cruzi in these countries [3]. In non-endemic regions, the parasite can be transmitted vertically (congenital transmission from mother to fetus), and by infected blood and organ donors [4].

In 2008, more than 38 million migrants were living in Europe, of whom $11 \%$ came from Latin America [5]. This figure did not include migrants without valid residency permit (irregular, undocumented migrants) [6], people born outside Europe who have acquired citizenship of a European country, or children from foreign countries adopted by European families. Official figures thus clearly underestimate the number of migrants from endemic areas, and therefore also the number of T. cruzi-infected people.

Currently, only a small number of persons infected with T. cruzi have been detected in Europe [4]. Several reasons account for this fact: 
- Most European health professionals have little or no experience with the detection and management of Chagas disease [7].

- Access to screening programmes for the communities at risk is very limited as only a few institutions offer screening, mostly in major urban areas.

- The diagnosis of the chronic phase is usually delayed as most patients remain asymptomatic for many years [8].

There is no common European legislation to prevent the transmission of $T$. cruzi by blood donation, although in Spain and France screening of Latin American donors is mandatory, while in countries like Italy or the United Kingdom (UK) blood donation by migrants from endemic Latin American countries is prohibited and their country of origin is recorded by questionnaire [4].

Only some autonomous communities of Spain, such as Valencia [9] and Catalonia [10], have protocols for screening of pregnant women from Latin America to prevent congenital transmission. The rest of Spain and other European countries, except for some focal institutional experiences [11], have not adopted any governmental preventive measures yet.

Very few studies have estimated the prevalence of Chagas disease in European countries [12-15]. In Spain, it was estimated that between 40,000 and 65,000 residents were infected with $T$. cruzi in 2009 [4], while in other European countries the estimate range was between 12,000 and 15,000 [16].

The lack of an information system to report Chagas disease cases and transmission in all European countries makes it difficult to provide an overall figure of all diagnosed cases in Europe so far, and therefore no exact overview of the burden and public health impact of Chagas disease in Europe can be made.

For this reason, the World Health Organization (WHO) set up in 2009 a working group of experts on Chagas disease from those European countries where T. cruzi-positive cases had been detected (Austria, Belgium, Croatia, Denmark, France, Germany, Italy, the Netherlands, Portugal, Romania, Spain, Sweden, Switzerland and United Kingdom). The aim was to collect and asses the available information, create a network of experts to exchange information and experience between countries and define a common strategy for the epidemiological surveillance of Chagas disease [17].

This paper presents the efforts of this group of experts to provide a preliminary view of the situation in Europe, using a consensual, homogeneous methodology. The objectives of this study were to estimate the expected and observed prevalence of cases of $T$. cruzi-infected people from endemic countries of origin, the annual incidence of congenital transmission and the estimated rate of underdiagnosis among cases of $T$. cruzi infection in 2009 in the participating countries.

\section{Methods}

Study design and population

An epidemiological study was designed to analyse aggregate measures of the prevalence of $T$. cruzi infection and the incidence of congenital transmission of Chagas disease in 2009. The units of observation were the European countries that according to the WHO estimate, had more than 400 cases of Chagas disease [4], i.e. Belgium, France, Germany, Italy, the Netherlands, Portugal, Spain, Switzerland and the UK.

\section{Case definition}

For the purposes of this study, according to the WHO case definition [18], a case of Chagas disease was considered as any individual who, as a result of a screening programme or of testing as a possible case, was positive for antibodies against $T$. cruzi in two serological (ELISA) assays.

\section{Inclusion and exclusion criteria}

The target population included three categories:

- Subjects of any age born in countries endemic for Chagas disease who were regular residents of the above-mentioned European countries in the year 2009 or the latest year for which this information was available.

- The undocumented migrants from disease endemic countries resident in the above-mentioned European countries.

- Children born in countries endemic for Chagas disease and adopted by families from the above-mentioned European countries.

Latin Americans not born in countries endemic for Chagas disease (e.g. the Caribbean islands) were excluded.

European travellers to endemic countries and cases of Chagas disease diagnosed in European travellers presumably infected in endemic countries were excluded due to the small expected number of cases and the difficulty in obtaining information about them.

\section{Information sources}

The study population was quantified using official published data obtained from national institutions in the included European countries, Eurostat and data collected by the working group and collaborators of the project. All these sources are listed in Table 1 and the corresponding data are shown in Table 2.

The numbers of diagnosed cases of Chagas disease in each European country was provided by members of the national reference institutions and members of the WHO working group. 
The infection rates used to calculate the expected prevalence rate among the estimated resident population of Latin Americans in European countries (Table 3) were those published by the WHO in 2006 [19]. The rates for Bolivia were calculated according to available data on the Bolivian population living in Europe $[20,21]$. The rates for French Guyana and Surinam were provided respectively by the Institute of Health
Surveillance (Institut de Veille Sanitaire, France) and by the Department of Medical Microbiology of the University of Amsterdam (the Netherlands) and rely on estimations on immigrants from these countries living in Europe.

\section{TABLE 1}

Information sources for estimates of migrant residents (legal and undocumented), adoptions and annual births in nine studied European countries

\begin{tabular}{|c|c|c|}
\hline Country & Category & Institution and reference year \\
\hline \multirow{4}{*}{ Belgium } & Legal immigration & $\begin{array}{l}\text { National register, Directorate of Statistics and Economic Information (DGSIE), } \\
2006\end{array}$ \\
\hline & Estimated undocumented immigration & Faculty of Medicine, Free University of Bruxelles, Brussels, Belgium 2006 \\
\hline & Adoptions & $\begin{array}{l}\text { Adoption in French and Dutch-speaking Belgium, Belgian Directorate of } \\
\text { adoption, 2001-2009 }\end{array}$ \\
\hline & Annual births & $\begin{array}{l}\text { National register, Directorate of Statistics and Economic Information (DGSIE), } \\
2006\end{array}$ \\
\hline \multirow{4}{*}{ France } & Legal immigration & Institute of Health Surveillance (INVS), 2008 \\
\hline & Estimated undocumented immigration & Institute of Health Surveillance (INVS), 2008 \\
\hline & Adoptions & Institute of Health Surveillance (INVS), 1980-2007 \\
\hline & Annual births & Institute of Health Surveillance (INVS), 2008 \\
\hline Germany & Legal immigration & Eurostat, 2008 \\
\hline \multirow{4}{*}{ Italy } & Legal immigration & Italian National Institute of Statistics (ISTAT), 2009 \\
\hline & Estimated undocumented immigration & $\begin{array}{l}\text { Centre for Tropical Diseases, Hospital Ospedale Sacro Cuore Don Calabria, } \\
\text { Verona, Italy, } 2009\end{array}$ \\
\hline & Adoptions & $\begin{array}{l}\text { Commission for international adoptions, Presidency of the Council of Ministers, } \\
2000-2009\end{array}$ \\
\hline & Annual births & ISTAT, 2008 \\
\hline \multirow{2}{*}{ the Netherlands } & Legal immigration & Statistics Netherlands, 2008 \\
\hline & Estimated undocumented immigration & Central government (Rijksoverheid), 2005 \\
\hline \multirow{3}{*}{ Portugal } & Legal immigration & Statistics Portugal (INE), 2009 \\
\hline & Estimated undocumented immigration & $\begin{array}{l}\text { Institute of Hygiene and Tropical Medicine, New University of Lisbon, Lisbon, } \\
\text { Portugal }\end{array}$ \\
\hline & Annual births & INE Portugal, 2009 \\
\hline \multirow{4}{*}{ Spain } & Legal immigration & Statistics Spain (INE), 2009 \\
\hline & Estimated undocumented immigration & Statistics Spain (INE), 2009 \\
\hline & Adoptions & Statistics Spain (INE), 2000-2007 \\
\hline & Annual births & Statistics Spain (INE), 2008 \\
\hline \multirow{4}{*}{ Switzerland } & Legal immigration & Federal departement of justice and police, 2009 \\
\hline & Estimated undocumented immigration & $\begin{array}{l}\text { Division of primary care medicine, Geneva University Hospitals and University } \\
\text { of Geneva, Geneva, Switzerland, } 2009\end{array}$ \\
\hline & Adoptions & Federal office of statistics, Section demography and migration, 1979-2008 \\
\hline & Annual births & Demographic portrait of Switzerland, 2008 \\
\hline \multirow{3}{*}{ United Kingdom } & Legal immigration & Office for National Statistics, Social Surveys Dataservice, 2009 \\
\hline & Estimated undocumented immigration & $\begin{array}{l}\text { 1. Sveinsson, Kjartan Páll. Bolivians In London - Challenges and Achievements } \\
\text { of a London Community, Runnymede Community Studies, Runnymede Trust. } \\
2007 \\
\text { 2. Buchuck S. Crossing borders: Latin American exiles in London. Untold } \\
\text { London, } 2010 \\
\text { 3. Bérubé M. Colombia: In the crossfire. Migration Information Source. } \\
\text { Migration Policy Institute. } 2005 \\
\text { 4. James M. Ecuadorian identity, community and multi-cultural integration. } \\
\text { Runnymede Trust. } 2005\end{array}$ \\
\hline & Annual births & Office for National Statistics, Vital Statistics Outputs Branch, 2009 \\
\hline
\end{tabular}


The applied rates of congenital transmission (1.4\% and $7.3 \%$ ) came from cohorts of migrant pregnant women living in Europe $[11,22]$.

\section{Data collection and analysis}

To estimate the expected prevalence of $T$. cruziinfected people in the studied countries, we first calculated the number of regular residents originating from endemic countries, according to the data published by the national statistical institutes in each country. When there were no published data, these were obtained from governmental sources or from members of the working group (Table 1).

To calculate the undocumented migrant population, we used estimates from governmental sources, national referral centres and indexed and non-indexed publications (Table 1). In the case of Spain, the official number of regular residents was subtracted from the number of migrants included in the municipal census.

In the case of children born in endemic countries and adopted by European families, we sought official data sources on adoption by country of birth (Table 1). The inclusion of this population in the study depended on the availability of data on adoptions, and finally data from five countries (Belgium, France, Italy, Spain, and Switzerland) were included.

To obtain the expected absolute number of cases of $T$. cruzi infection, the number of regular and undocumented migrants from Latin America and the number of adopted children, stratified by country of origin, was multiplied by the corresponding national infection rates in the countries of origin. A two-sided confidence intervals method with continuity correction for the single proportion [23] was applied to calculate the expected number of cases in migrants for every endemic country of origin. The expected number of cases obtained was divided by the corresponding reference population to obtain the expected prevalence rate (shown as percentage). In the case of minimum and maximum values for reference population, an average value was applied to calculate the expected prevalence.

To calculate the observed prevalence of $T$. cruzi-infected people, the members of the working group were asked to actively search for cases diagnosed in their country up to the year 2009, dividing this amount by the total reference population to obtain the observed prevalence rate, shown as percentage.

To estimate the expected annual incidence of congenital transmission, national data on annual births of children of women from endemic areas stratified by country of birth or nationality of the mother as registered in $\mathbf{2 0 0 9}$ or the latest year available was collected (Table 1). These figures were multiplied by the respective rates of infection in endemic countries, which provided an estimate of the absolute number of mothers infected with $T$. cruzi who gave birth in one year. Applying the range of congenital transmission rates $(1.4 \%$ to $7.3 \%)$ to this result gave an estimate of the number of $T$. cruzi-infected children born in each participating European country. The annual incidence rate of congenital transmission in the population at risk was obtained by dividing the number of children infected in one year by the number of pregnancies in that year.

To estimate the index of underdiagnosis we calculated the rate ratio between the observed and expected prevalence rates. The result represents the proportion of diagnosed cases divided by the total estimated cases. The index is presented as a percentage obtained from the following formula: 1-rate ratio.

\section{TABLE 2}

Estimates of migrants resident in nine studied European countries, legal and undocumented, originating from countries endemic for Chagas disease, and births to mothers from endemic countries, 2009

\begin{tabular}{|c|c|c|c|c|c|c|c|c|c|c|}
\hline \multirow{3}{*}{ Country } & \multicolumn{8}{|c|}{ Resident immigrants } & \multirow{2}{*}{\multicolumn{2}{|c|}{ Annual births }} \\
\hline & \multicolumn{2}{|c|}{$\begin{array}{r}\text { Regular } \\
\text { population }\end{array}$} & \multicolumn{2}{|c|}{$\begin{array}{r}\text { Estimated undocumented } \\
(\min -\max )\end{array}$} & \multicolumn{2}{|c|}{ Adoptions } & \multicolumn{2}{|c|}{ Total (min-max) } & & \\
\hline & $\mathrm{Nb}$ & $\%$ & $\mathrm{Nb}$ & $\%^{\mathrm{a}}$ & $\mathrm{Nb}$ & $\%$ & $\mathrm{Nb}$ & $\%^{\mathrm{a}}$ & $\mathrm{Nb}$ & $\%$ \\
\hline Belgium & 28,880 & 1 & 14,440 & 1 & 490 & 1 & 43,810 & 1 & 722 & 1 \\
\hline France & 97,981 & 4 & 51,500 & 5 & 19,389 & 51 & 168,870 & 5 & 5,545 & 10 \\
\hline Germany & 85,313 & 4 & Not reported & - & Not reported & - & 85,313 & 3 & Not reported & - \\
\hline Italy & 260,864 & 12 & $112,000-120,000$ & 11 & 6,784 & 18 & $379,648-387,648$ & 12 & 3,351 & 6 \\
\hline The Netherlands & 220,172 & 10 & 17,400 & 2 & Not reported & - & 237,572 & 7 & Not reported & - \\
\hline Portugal & 110,113 & 5 & 11,011 & 1 & Not reported & - & 121,124 & 4 & 3,950 & 7 \\
\hline Spain & $1,263,342$ & 56 & 484,509 & 47 & 6,354 & 17 & $1,754,205$ & 53 & 35,525 & 67 \\
\hline Switzerland & 35,761 & 2 & $38,000-42,000$ & 4 & 4,994 & 13 & $78,755-82,755$ & 2 & 375 & 1 \\
\hline United Kingdom & 162,517 & 7 & $250,000-335,000$ & 28 & Not reported & - & $412,517-497,517$ & 14 & 3,433 & 6 \\
\hline Total & $2,264,943$ & $101^{\mathrm{b}}$ & $978,860-1,075,860$ & $99^{\mathrm{b}}$ & 38,011 & 100 & $3.281,814-3,378,814$ & $101^{\mathrm{b}}$ & 52,901 & $98^{b}$ \\
\hline
\end{tabular}

\footnotetext{
a In the case of minimum and maximum values, the percentage refers to the average value.
}

b The deviation is due to rounding. 


\section{Results}

More than three million migrants from endemic countries (MEC) were estimated to live in the nine European countries included in the study, representing $1 \%$ of the total population living in Europe. Due to immigration from Brazil, Portugal was the country with the highest percentage of migrants coming from endemic areas. Among the countries where no Romance language is spoken, the Netherlands had the highest percentage of migrants coming from endemic countries, mainly from Surinam ( $84 \%$ of MEC in the Netherlands), a former Dutch colony and an endemic country for Chagas disease with a low infection rate.
Prevalence in migrants and adoptees

For details about MEC living in Europe, multiple sources of information were used (Tables 1 and 2). However, it was not possible to identify all people at risk due to the lack of data stratified by endemic country. Between 40,227 and 62,724 people infected with $T$. cruzi resided regularly in the included countries, accounting for between $1.8 \%$ and $2.8 \%$ of all regular MEC (Table 4 ). The highest prevalence estimation for regular MEC was seen in Spain, where between $2.3 \%$ and 3.8\% of them were infected with $T$. cruzi.

The estimated numbers of undocumented MEC infected by $T$. cruzi were very high: prevalence estimations were substantially higher than for regular MEC, with the

TABLE 3

Distribution of the migrant population from countries endemic for Chagas disease resident in nine studied European countries, and estimated number of people infected, 2009

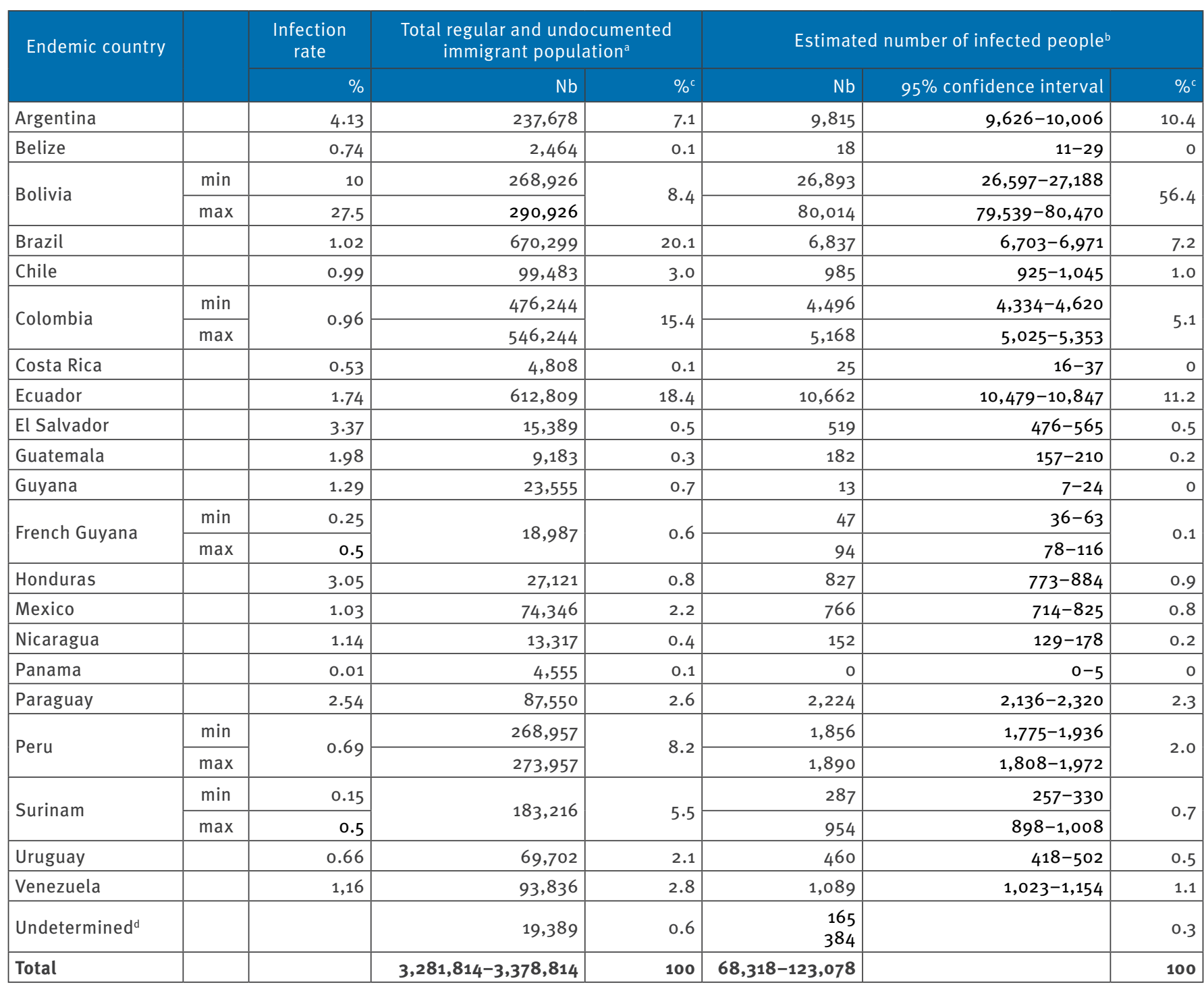

a The total immigrant population from Bolivia, Colombia and Peru is a range of values due to estimations of undocumented population.

b Estimates based on infection rate of the country of origin.

In the case of minimum and maximum values, the percentage refers to the average value.

d This number refers to adoption in France, for which no data is available stratified by endemic country, and the estimate of people infected was calculated by the Institut de Veille Sanitaire, France. 
highest estimated prevalence in Spain (between 3.9\% and $7.8 \%$ of undocumented MEC), and Switzerland (between $2.5 \%$ and $7.8 \%$ of undocumented MEC).

France had the highest number of positive cases among children adopted from endemic countries, although these were from countries with low infection rates. Cases represented between $0.8 \%$ and $2 \%$ of French adoptions from endemic countries. The overall expected prevalence in the participating countries ranged from $1.2 \%$ to $2.4 \%$ of total adoptions of children from endemic settings.

\section{Congenital transmission}

In the studied countries almost 53,000 children were born in 2009 from mothers originating from endemic countries. Of these, between 1,347 and 2,521 were born from mothers infected with $T$. cruzi, and there was congenital transmission in between 20 and 184 cases. This corresponds to between none and three infected children per 1,000 births to mothers at risk (Table 5). With $67 \%$ of births from mothers originating from endemic countries occurring in Spain, almost $90 \%$ all of cases of congenital transmission occurred in that country. In other countries, there were between none and six cases of congenital transmission per year.

\section{Underdiagnosis}

By $2009,4,290$ cases of infection with $T$. cruzi were diagnosed in the study countries (Table 6), and $89 \%$ of all cases were detected in Spain. The total observed prevalence rate was $0.13 \%$ of the total MEC. The lowest observed rates occurred in Germany $(0.002 \%)$ and the Netherlands (0.003\%) and the highest in Switzerland (0.223\%).

The index of underdiagnosis shows that, in general, between $94 \%$ and $96 \%$ of expected cases were not diagnosed (Table 6). The index of underdiagnosis was lowest in Switzerland, where between $89 \%$ and $95 \%$ of expected cases were not detected, while in Germany, the Netherlands, Portugal and the UK, more than $99 \%$ of expected cases in migrants were not diagnosed.

Overall, the Latin American nationalities with the greatest presence in Europe were Brazilans, Colombians and Ecuadorians, although most expected cases of Chagas were attributed to Bolivian migrants (Table 3).

\section{Discussion}

The Control of Chagas disease is a recent public health challenge in many countries in Europe. The reason is that it is an imported disease mainly affecting the migrated poor population from different Latin American countries who often have limited access to diagnosis and treatment of this disease. This also makes it difficult to quantify the disease impact in terms of expected cases. However, it is a challenge that requires urgent action due to the risks involved in the context of blood, organ and tissue donation, and the risk of congenital transmission to infants of infected mothers. In addition, the presence of potentially infected population groups who may present with heart, digestive tract and general disorders in the medium and long term, needs to be considered also with a view to the individual patient and the impact on clinical costs.

To quantify the European expected prevalence the authors decided to use initially the WHO official infection rates for every disease endemic country [18]. On the other hand, it was observed that all prevalence studies on Latin American immigrants living in Europe showed rates in the Bolivian community higher than the $6,75 \%$ WHO official estimated rate $[20,21,24,25]$. For this reason we preferred to use a more realistic range for Bolivian migrants (minimum $10.0 \%$, maximum $27.5 \%$ ) that was based on the known epidemiological situation in Europe. This choice could have introduced some bias at the methodological level by elevating the results in only one community. Nevertheless, the authors believe that this decision was necessary because the final results were closer to the reality that

TABLE 4

Estimated numbers of migrants from Chagas disease-endemic countries infected with Trypanosoma cruzi and expected prevalence in the nine studied European countries in 2009

\begin{tabular}{|c|c|c|c|c|c|c|c|c|}
\hline \multirow{2}{*}{$\begin{array}{l}\text { Country } \\
\text { Belgium }\end{array}$} & \multicolumn{2}{|c|}{ Legal (min-max) } & \multirow{2}{*}{\multicolumn{2}{|c|}{$\begin{array}{l}\text { Estimated undocumented } \\
\text { (min-max) } \\
\text { Prevalence }\end{array}$}} & \multirow{2}{*}{\multicolumn{2}{|c|}{$\begin{array}{r}\text { Adoptions (min-max) } \\
\text { Prevalence }\end{array}$}} & \multirow{2}{*}{\multicolumn{2}{|c|}{$\begin{array}{l}\text { Total (min-max) } \\
\text { Prevalence }\end{array}$}} \\
\hline & \multicolumn{2}{|c|}{ Prevalence } & & & & & & \\
\hline France & $1,253-1,542$ & $1.3-1.6$ & $730-897$ & $1.4-1.7$ & $165-384$ & $0.8-2$ & $2,148-2,823$ & $1.3-1.7$ \\
\hline Germany & $1,123-1,481$ & $1.3-1.7$ & Not reported & - & Not reported & - & $1,123-1,481$ & $1.3-1.7$ \\
\hline Italy & $4,133-5,322$ & 1.6-2 & $2,220-6,520$ & $1.9-5.6$ & 111-194 & $1.6-2.9$ & $6,464-12,036$ & $1.7-3.1$ \\
\hline Netherlands & $776-1,528$ & $0.3-0.7$ & $191-245$ & 1.1-1.4 & Not reported & - & 967-1773 & $0.4-0.7$ \\
\hline Portugal & 1,141 & 1 & 114 & 1 & Not reported & - & 1,255 & 1 \\
\hline Spain & $28,974-48,510$ & $2.3-3.8$ & $18,884-37,874$ & $3.9-7.8$ & $126-234$ & $2-3 \cdot 7$ & $47,984-86,618$ & $2.7-4 \cdot 9$ \\
\hline Switzerland & $535-750$ & $1.5-2.1$ & $982-3,132$ & $2.5-7.8$ & 66-88 & $1.3-1.8$ & $1,584-3971$ & $2-4.8$ \\
\hline United Kingdom & $1,841-1,849$ & 1.1 & $4,270-10,352$ & $1.5-3 \cdot 5$ & - & - & $6,111-12,201$ & $1.3-2.4$ \\
\hline Total & $40,227-62,724$ & $1.8-2.8$ & $27,617-59,435$ & $2.7-5.8$ & 474-919 & $1.2-2.4$ & $68,318-123,078$ & $2-3.6$ \\
\hline
\end{tabular}


professionals involved in the detection of cases see every day in health systems.

Another relevant point is that other applied national infection rates, based on the population in diseaseendemic countries, do not take into account the effects of heterogeneity of the immigrant population living in Europe (i.e. age groups, socio-economic differences, rural-urban origin, etc.) and these differences are not reflected in the results.

The results of this study highlight the difficulty in obtaining accurate data on the population at risk and specific information on diagnosed cases, the lack of official national data, the underestimation of migrants in the official figures, and the lack of a system for reporting detected cases in non-endemic countries.

According to the estimations of expected cases in the different non-endemic countries, and to offer a better view of the situation, we classified the countries in three groups. The first category includes only Spain, which accounts for almost $75 \%$ of expected cases. The second group is represented by France, Italy and the UK, while the third group is represented by the other non-endemic countries (Belgium, Germany, the Netherlands, Portugal and Switzerland). The key role played by Spain in the prevention and control of Chagas disease in Europe is not only due to the high expected prevalence of $T$. cruzi infection, but also relates to its pivotal position in the migrant flow to Europe and the cultural and linguistic proximity to Latin American countries. France has played a key role in the development of recent studies and specific interventions and regulations for Chagas disease [26], although the country had a low expected number of cases. This and the existence of French national territory in the endemic region of Latin America (French Guyana) places France in a distinctive position in the prevention and control plans for Chagas disease in non-endemic European countries.

\section{TABLE 5}

Estimated congenital transmission and prevalence rate per 1,000 pregnancies in women from Chagas disease-endemic areas, residing in nine studied European countries, 2009

\begin{tabular}{|c|c|c|c|c|c|}
\hline \multirow{2}{*}{ Country } & \multirow{2}{*}{ Annual births } & \multicolumn{2}{|c|}{ Infected pregnant women (min-max) } & \multicolumn{2}{|c|}{ Infected infants (min-max) } \\
\hline & & $\begin{array}{l}\text { Number } \\
\text { of cases }\end{array}$ & $\begin{array}{c}\text { Cases per } 1,000 \\
\text { pregnancies }\end{array}$ & $\begin{array}{l}\text { Number } \\
\text { of cases }\end{array}$ & $\begin{array}{c}\text { Cases per } 1,000 \\
\text { pregnancies }\end{array}$ \\
\hline Belgium & 722 & $10-13$ & $14-18$ & $0-1$ & $\ll 1$ \\
\hline France & 5,545 & $53-74$ & $10-13$ & $1-5$ & $\ll 1$ \\
\hline Germany & Not reported & Not applicable & - & Not applicable & - \\
\hline Italy & 3,351 & $55-76$ & $16-23$ & $1-6$ & 1 \\
\hline The Netherlands & Not reported & Not applicable & - & Not applicable & - \\
\hline Portugal & 3,950 & 40 & 10 & $1-3$ & $\ll 1$ \\
\hline Spain & 35,525 & $1,125-2,226$ & $32-63$ & $16-162$ & $0-5$ \\
\hline Switzerland & 375 & $6-8$ & $16-21$ & $0-1$ & 1 \\
\hline United Kingdom & 3,433 & $58-84$ & $17-24$ & $1-6$ & 1 \\
\hline Total & 52,901 & $1,347-2,521$ & $25-48$ & $20-184$ & $0-3$ \\
\hline
\end{tabular}

\section{TABLE 6}

Diagnosed cases, observed and expected prevalence rates and percentage of underdiagnosis of Chagas disease in migrants from endemic areas residing in nine studied European countries, up to 2009

\begin{tabular}{|l|c|c|c|c|}
\hline Country & Cases diagnosed & $\begin{array}{c}\text { Observed prevalence rate } \\
(\%)\end{array}$ & $\begin{array}{c}\text { Expected prevalence rate } \\
(\text { min-max, \%) }\end{array}$ & $\begin{array}{c}\text { Index of underdiagnosis } \\
\text { (min-max, \%) }\end{array}$ \\
\hline Belgium & 19 & 0.043 & $1,6-2.1$ & $97.2-97.9$ \\
\hline France & 111 & 0.066 & $1.3-1.7$ & $94.8-96.1$ \\
\hline Germany & 2 & 0.002 & $1.3-1.7$ & $99.8-99.9$ \\
\hline Italy & 114 & 0.03 & $1.7-3.1$ & $98.3-99.0$ \\
\hline The Netherlands & 7 & 0.003 & $0.4-0.7$ & $99.3-99.6$ \\
\hline Portugal & 8 & 0.007 & 1 & 99.4 \\
\hline Spain & 3,821 & 0.218 & $2.7-4.9$ & $92.0-95.6$ \\
\hline Switzerland & 180 & 0.223 & $\mathbf{2 - 4 . 8}$ & $89.2-95.2$ \\
\hline United Kingdom & 28 & 0.006 & $\mathbf{2 - 3}-2.4$ & $99.6-99.7$ \\
\hline Total & $\mathbf{4 , 2 9 0}$ & $\mathbf{0 . 1 3}$ & & $93.9-96.4$ \\
\hline
\end{tabular}


The observed prevalence was extremely low, compared with the expected rates, in Belgium, the Netherlands, Portugal and the UK, suggesting a lack of awareness and interventions (protocols, studies, etc) against Chagas disease in those countries. The UK, especially London where most Latin American immigrants to the UK reside [27], ranks second in Europe in terms of residents estimated to be infected with $T$. cruzi and cases of congenital transmission, with numbers nearly identical to those of Italy. These results are entirely novel and in contrast to UK estimates published in previous studies [16]. This discrepancy could be due to potential underestimation in official statistics of the Latin American population actually resident in the UK.

The study highlights the presence of positive cases in undocumented migrants, especially in Spain, Italy and Switzerland. These countries have large Bolivian communities not represented in official statistics $[24,28]$ that makes it even harder for the national authorities to identify the population at risk. On the other hand these results can offer only an incomplete picture of the reality due to the limitations of estimating the reference population. Nevertheless the present study offers new information not included in previous studies that only included documented migrants $[3,15]$. The fact that being an undocumented migrant could be associated with originating from poor endemic areas with higher prevalence rates highlights the value of developing demographic studies that can contribute to providing more reliable estimates of this population.

The estimated results on underdiagnosis are a good indicator of the limited epidemiological impact of Chagas disease in the context of European health and surveillance systems. Epidemiological silence, understood as the lack of detected cases, which is common in some European countries, shows the need for greater involvement of European health authorities in controlling neglected tropical diseases, among others Chagas disease. The priority could be the implementation of screening programmes of target populations and the training of professionals in the detection of possible cases. The legislation or protocols already implemented in countries such as Spain or France would be very useful to reduce the differences in preparedness and available programmes between European countries. Such collaboration would be of help in developing a European surveillance system, which is essential for further progress in controlling Chagas disease.

The control of congenital transmission is undoubtedly one of the most important measures for the prevention and control of Chagas disease that should be addressed by surveillance systems because of the effectiveness of treatment in infants. Likewise, the establishment of regulations for blood and organ donation is essential to limit the impact of Chagas disease in countries where there is no vector transmission. Systematic screening of the risk population, at present only carried out in some regions of France, Spain and
Switzerland, should also be introduced after carrying out cost-effectiveness analyses to decide which measures could be most appropriate.

In terms of public health, the authors believe that the main proposals and challenges for European countries where cases have already been identified or that have residents from endemic areas are:

- To create an international information and surveillance system for the reporting of cases, control of transmission, exchange of information between European countries, and training of primary healthcare workers.

- To carry out studies to define the risk of congenital transmission in pregnant women from Latin America and to evaluate the impact of potential screening protocols for the control of congenital transmission according to the results obtained.

- To carry out epidemiological studies allowing for reliable estimation of true prevalence rates among immigrants resident in Europe.

- To consider systematic screening (by questionnaire or serological tests) blood, organ and tissue donors from endemic Latin American regions.

- To publish official statistics of migrants from Chagas-endemic countries in each European country containing data by regular and irregular status according to their country of origin.

- To facilitate access to diagnosis and treatment to groups of migrants at risk of being excluded from the national health systems such as undocumented immigrants.

- To reinforce the teaching on international health and tropical diseases in the curricula of health sciences in European Universities.

Acknowledgments

In addition to the members of the working group on Chagas disease in Europe, we would like to thank the collaboration of: Dr. Zeno Bisoffi (Centro per le Malattie Tropicali, Ospedale S. Cuore, Don Calabria, Negrar, Verona. COHEMI network), Dr. Manuel Segovia (Hospital Universitario Virgen de la Arrixaca, Murcia, Spain), Dr. Pere Godoy (Departament de Salut, Generalitat de Catalunya, Barcelona, Spain), Ms. Beatriz Camps Carmona (WHO Programme on Control of Chagas disease, Department of Control of Neglected Tropical Diseases, WHO, Geneva, Switzerland), Ms. Mar Velarde (WHO Programme on Control of Chagas disease, Department of Control of Neglected Tropical Diseases, WHO, Geneva, Switzerland)

The study presented in this article is part of a European project called "Development of a system of epidemiological surveillance for Chagas disease in Europe" financed by the WHO Programme on Control of Chagas disease, Innovative \& Intensified Disease Management, Department of Control of Neglected Tropical Diseases)

Members of the Working Group on Chagas Disease in Europe: Apart from the authors of this article, the present working group is composed of: 
Dr. Mariella Anselmi (Centro per le Malattie Tropicali, Ospedale S. Cuore, Don Calabria, Negrar, Verona, Italy. COHEMI network), Dr. Luigi Gradoni (Dipartimento di Malattie Infettive, Parassitarie e Immunomediate, Istituto Superiore di Sanità, Roma, Italy), Dr. José Antonio Pérez Molina (Hospital Ramon y Cajal, Madrid, Spain), Dr. Joaquim Gascón (Hospital Clínic, Barcelona, Spain. COHEMI network), Dr. Jordi Gomez i Prat (Centre de Salut Internacional i Medicina Tropical Drassanes, Barcelona, Spain), Dr. Luisa Sánchez Serrano (Instituto de Salud Carlos III, Madrid, Spain), Dr. Magdalena García (Consorcio Hospital General Universitario de Valencia, Valencia, Spain), Dr. Bartolomé Carrilero Fernández (Hospital Universitario Virgen de la Arrixaca, Murcia, Spain), Dr. Jane Jones (Health Protection Agency, London, UK), Dr. Emmanuel Bottieau (Institute of Tropical Medicine, Antwerp, Belgium), Dr. Xavier Lescure (Hôpital Tenon, Paris, France), Dr. Pierre Ambroise-Thomas (Académie nationale de Médecine, Meylan, France), Dr. Jean Delmont (Centre de formation et recherche en médecine et sante tropicales, Marseille, France), Dr. Guillaume Le Loup (Service de Maladies infectieuses tropicales, Hôpital Tenon, Paris, France), Dr. Luc Paris (Service de Parasitologie-Mycologie, Groupe Hospitalier Pitié-Salpêtrière, Paris, France), Dr. Françoise Gay-Andrieu (Laboratoire de ParasitologieMycologie, Institut de Biologie - Hôtel Dieu, Nantes, France), Dr. Aldert Bart (Parasitology Section, Dept Med Microbiol, Academic Medical Center, Amsterdam, the Netherlands), Dr. August Stich (Tropenmedizin Missionsärztliche Klinik, Würzburg, Germany), Dr. Israel Molina (Hospital Vall d'Hebron, Barcelona, Spain), Dr. Carmen Muñoz (Hospital Sant Pau, Barcelona, Spain), Dr. Carmen Cabellos (Hospital de Bellvitge, Barcelona, Spain), Dr. Lluis Valerio (Unitat de Salut International Metropolitana Nord, Barcelona, Spain), Dr. Angel Lluis Ballesteros (Hospital de Badalona, Barcelona, Spain), Dr. Cristina Soler (Hospital de Santa Caterina, Girona, Spain), Dr. Toni Soriano (Hospital Joan XXIII, Tarragona, Spain) and Dr. Jean Jannin (Innovative and Intensified Disease Management Unit, Department of Control of Neglected Tropical Diseases, WHO, Geneva, Switzerland)

\section{References}

1. World Health Organization (WHO). Working to overcome the global impact of neglected tropical diseases: first WHO report on neglected tropical diseases. Geneva: WHO; 2010. Report No.: WHO/HTM/NTD/2010.1. Available from: http://whqlibdoc. who.int/publications/2010/9789241564090 eng.pdf

2. Dias JC, Silveira AC, Schofield CJ. The impact of Chagas disease control in Latin America: a review. Mem Inst Oswaldo Cruz. 2002;97(5): 603-12.

3. Schmunis GA, Yadon ZE. Chagas disease: A Latin American health problem becoming a world health problem. Acta Trop. 2010;115(1-2):14-21.

4. World Health Organization (WHO). Control and prevention of Chagas disease in Europe. Report of a WHO Informal Consultation (jointly organized by WHO headquarters and the WHO Regional Office for Europe) Geneva, Switzerland, 17-18 December 2009. Final report. Geneva: WHO; 2010. Report No.: WHO/HTM/NTD/IDM/2010.1. Available from: http://www. fac.org.ar/1/comites/chagas/Chagas_WHO Technical\%20 Report_16_06_10.pdf

5. Vasileva K. Statistics in focus. Citizens of European countries account for the majority of the foreign population in EU-27 in 2008. Luxembourg: Eurostat; 2009. Report No.: 94/2009. Available from: http://epp.eurostat.ec.europa.eu/cache/ITY OFFPUB/KS-SF-09-094/EN/KS-SF-09-094-EN.PDF

6. European Commission (EC). Size and development of irregular migration to the EU, Clandestino Research Project, Counting the Uncountable: Data and Trends across Europe. Bruxelles: EC; 2009 [Accessed: 27 Feb 2011]. Available from: http:// clandestino.eliamep.gr/wp-content/uploads/2009/12/ clandestino_policy_brief_comparative_size-of-irregularmigration.p $\overline{d f}$

7. Jackson J, Angheben A, Carrilero Fernández B, Jansa i Lopez del Vallado JM, Jannin JG, Albajar-Viñas P. Prise en charge de la maladie de Chagas en Europe. Expériences et défis en Espagne, Suisse et Italie. [Management of Chagas disease in
Europe. Experiences and challenges in Spain, Switzerland and Italy]. Bull Soc Pathol Exot. 2009;102(5):326-9. French.

8. Rassi A Jr, Rassi A, Marin-Neto JA. Chagas disease. Lancet. 2010;375(9723):1388-402.

9. Autonomous Government of Valencian Community. Enfermedad de Chagas importada. Protocolo de actuación en la Comunitat Valenciana. [Imported Chagas Disease. Protocol of actions in the Valencian Community]. Valencia: Conselleria de Sanitat, Generalitat Valenciana; 2009 [Accessed: 14 Jun 2010]. Spanish. Available from: http://biblioteca.sp.san.gva.es/biblioteca/ publicaciones/MATERIAL/PUBLICACIONES/INFAN_MUJER/ PERINATAL/MAMUAL_ENF_CHAGAS.PDF

10. Autonomous Government of Catalonia. Protocol for screening and diagnosing Chagas disease in pregnant Latin American women and their newborns. Barcelona: Departament de Salut, Genaralitat de Catalunya; 2010 [Accessed: 14 Jun 2010]. Available from: http://www.gencat.cat/salut/depsalut/html/ en/dir3559/chagasprot_eng.pdf

11. Gonzalez-Granado L, Rojo P, Gonzalez-Tomé M, Camaño I, Salto E, Flores M. Cribado sistemático de la enfermedad de Chagas en embarazadas bolivianas y seguimiento de los recién nacidos. Experiencia de un año. [Systematic screening of Chagas Disease in Bolivian pregnant women and newborn follow-up. One-year experience]. Enf. Emerg. 2009;11 Supl1:1819. Spanish.

12. Salamanca DD, La Ruche G, Tarantola A, Degail MA, Jeannel D, Gastellu-Etchegorry M. Maladie de Chagas en France: estimation du nombre de personnes infectées et d'atteintes cardiaques en $\mathbf{2 0 0 9}$, selon les groups à risqué [Chagas disease in France: estimated number of infected persons and cardiac diseases in 2009, by risk groups].. Bull Soc Pathol Exot. 2009;102(5):285-90. French

13. Jackson Y, Gétaz L, Wolff H, Holst M, Mauris A, Tardin A, et al. Prevalence, Clinical Staging and Risk for Blood-Borne Transmission of Chagas Disease among Latin American Migrants in Geneva, Switzerland. PLoS Negl Trop Dis. 2010;4(2):e592.

14. Guerri-Guttenberg RA, Ciannameo A, Di Girolamo C, Milei J.Mal di Chagas : Un problema emergente di salute pubblica in Italia ? [Chagas disease: an emerging public health problem in Italy?]. Infez Med. 2009;17(1):5-13. Italian.

15. Pérez de Ayala A, Pérez-Molina JA, Norman F, López-Vélez R.. Chagasic cardiomyopathy in Immigrants from Latin America to Spain. Emerg Infect Dis. 2009;15(4):607-8.

16. Guerri-Guttenberg RA, Grana DR, Ambrosio G, Milei J. Chagas cardiomyopathy: Europe is not spared!. Eur Heart J. 2008;29(21):2587-91.

17. World Health Organization (WHO). New global effort to eliminate Chagas disease. Partners set out strategy against the 'kissing bug' disease. Geneva: WHO; 3 Jul 2007. Available from: http://www.who.int/mediacentre/news/releases/2007/ pr36/en/

18. World Health Organization (WHO). Control of Chagas disease. Technical report. Geneva: WHO; 2002. Available from: http:// whqlibdoc.who.int/trs/WHO_TRS_905.pdf

19. Pan American Health Organization (PAHO). Estimación cuantitativa de la enfermedad de Chagas en las Américas. [Quantitative estimation of Chagas Disease in the Americas]. Montevideo: PAHO; 2006. Report No.: OPS/HDM/CD/425-06. Spanish.

20. Piron M, Vergés M, Muñoz J, Casamitjana N, Sanz S, Maymó $\mathrm{RM}$, et al, Seroprevalence of Trypanosoma cruzi infection in at-risk blood donors in Catalonia (Spain). Transfusion. 2008;48(9):1862-8.

21. Muñoz J, Coll O, Juncosa T, Vergés $M$, del Pino $M$, Fumado V, et al. Prevalence and vertical transmission of Trypanosoma cruzi infection among pregnant Latin American women attending 2 maternity clinics in Barcelona, Spain. Clin Infect Dis. 2009;48(12):1736-40.

22. Yadon ZE, Schmunis GA. Congenital Chagas disease: Estimating the potential risk in the United States. Am.J.Trop. Med.Hyg. 2009;81(6):927-33.

23. Newcombe RG. Two-sided confidence intervals for the single proportion: comparison of seven methods. Stat Med. 1998;17(8):857-72.

24. Jackson Y, Myers C, Diana A, Marti HP, Wolff H, Chappuis F, et al. Congenital Transmission of Chagas Disease in Latin American Immigrants in Switzerland. Emerg Infect Dis. 2009; 15(4): 601-3.

25. Patricio-Talayero JM,,Benlloch-Muncharaz MJ, Collar-delCastillo J, Rubio-Soriano A, Serrat-Pérez C, Magraner-Egea J, et al. Vigilancia epidemiológica de la transmisión vertical de la enfermedad de Chagas en tres maternidades de la Comunidad Valenciana. [Epidemiological surveillance of verticallytransmitted Chagas disease at three maternity hospitals 
in the Valencian Community]. Enferm Infecc Microbiol Clin. 2008;26(10):609-13. Spanish.

26. Société de pathologie exotique. Atelier de consensus sur la Maladie de Chagas en zone non endémique (Paris - 26 Juin 2009). [Consensus workshop about the Chagas disease in non-endemic areas (26 June 2009, Paris, France)]. Bull Soc Pathol Exot. 2009;102(5):273-352. French.

27. BBC News. Born abroad, an immigration map of Britain, South America special report. London: BBC MMXII; 2010. [Accessed: 18 Jan 2011]. Available from: http://news.bbc.co.uk/2/shared/ spl/hi/uk/05/born_abroad/countries/html/south_america.stm

28. Orihuela M. Boliviani in Italia. [Bolivians in Italy].

Latinoamericando s.r.l., il portale del mondo latino. [

Latinoamericando Ltd., the portal of the Latin world.] 28 Jul

2009. Italian. Available from: http://www.latinoamericando.

it $/ \mathrm{cms} /$ index.php?option=com_flexicontent\&view=ite

$\mathrm{ms} \& \mathrm{cid}=51$ : focus-immigrazione $\&$ id $=3827$ : boliviani-in

italia\&ltemid=33\&lang=es 